\title{
Climate Change and Health
}

\section{Climate change: an emerging health issue}

\section{GUEST EDITORS}

\author{
Anthony G. Capon ${ }^{\mathrm{A}, \mathrm{B}}$ and Elizabeth G. Hanna ${ }^{\mathrm{A}}$ \\ ANational Centre for Epidemiology and Population Health, Australian National University \\ BCorresponding author.Email: tony.capon@anu.edu.au
}

The core concern is succinctly stated: climate change endangers health in fundamental ways.

Dr Margaret Chan, Director-General, World Health Organization on the occasion of World Health Day 2008.

The World Health Organization chose climate change as the theme for last year's World Health Day in an explicit attempt to attract policy-makers to the compelling evidence about the impacts of climate change on health. The reality of humaninduced climate change can no longer be doubted, but the extent of its consequences for health can still be reduced. Consideration of the health impacts of climate change can enable political leaders to act with the required urgency. ${ }^{1}$

Figure 1 illustrates the many ways in which climate change will affect health. ${ }^{2}$ There are likely to be some (modest) positive health consequences from climate change (for example, reduced extreme cold weather events in some locations); however, climate change will mostly have negative impacts on health. Climate change will affect health by changing the frequency and distribution of existing health problems. The health impacts of climate change will be greater in low-income communities; those who have contributed least to climate change will be affected the most. ${ }^{3}$

Climate change is currently high on the public policy agenda in Australia and around the world. A vitally important aspect of climate change policy is the opportunity of cobenefits for health from both mitigation and adaptation actions - examples include eating less meat; using renewable energy sources that reduce air pollution; and active modes of transport. ${ }^{4}$ This positive story is expected to be presented at the United Nations conference on climate change in Copenhagen later in 2009.

\section{Current actions}

The New South Wales (NSW) Government recognises climate change as a serious environmental, economic and social threat. The challenges posed by climate change have informed the NSW Greenhouse Plan, the current State Plan and the forthcoming Climate Action Plan. Box 1 provides a perspective on climate change and the NSW health system.

The Australian Government recently established the National Climate Change Adaptation Research Facility (NCCARF) at Queensland's Griffith University to generate information needed by decision-makers in government, and in vulnerable sectors and communities, to manage the risk of climate change impacts. A National Climate Change Adaptation Research Plan for Human Health has been published..$^{5}$ This plan will inform the work of a research network on this theme (Box 2).

\section{The papers in this issue}

Kjellstrom and Weaver present a succinct overview of climate change and health in Australia. The paper encompasses current and future threats facing Australians, including extreme weather events (storms, floods, heat waves), impacts on worker productivity, water supplies, air quality, vector- and foodborne disease, and impacts on mental health.

There are two papers identifying co-benefits for health from climate change actions. Rissel discusses active travel as an approach to climate change mitigation (reducing carbon dioxide emissions from fossil fuel use in motorised transport) that also has myriad human health benefits. This paper outlines strategies for health and urban planners to increase cycling, and uses Australian examples to illustrate the co-benefits of active travel. Dixon and colleagues focus on 


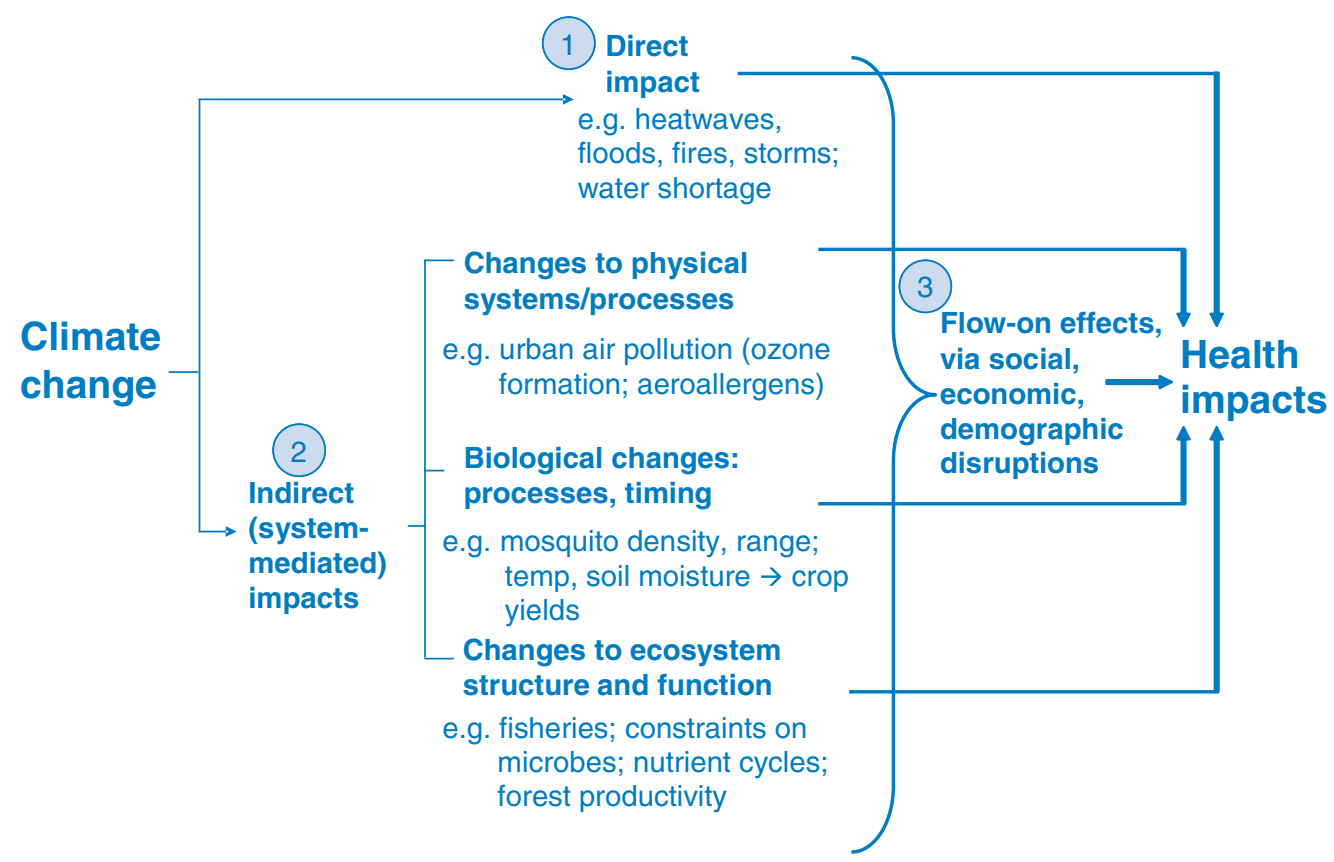

Figure 1. Putative pathways between climate change and health impacts. Used with permission from AJ McMichael.

\section{Box 1. Climate change and the NSW health system}

\section{Adam Craig \\ Environmental Health Branch, NSW Department of Health}

NSW Health is the largest consumer of energy and water of all NSW government agencies and has a commitment to minimise the environmental pollution resulting from the ongoing provision of public health services in NSW. This commitment is articulated in the NSW Government's Sustainability Strategy to reduce greenhouse gas emissions through energy savings and water use.

Developing adaptive responses to the inevitable impacts of climate change on health is another important challenge. Some adaptive strategies will entail revision or extension of existing public health and health planning policies and practices, while others will require innovative actions. Many will require co-ordinated action across components of the health system and by government, industry and community more broadly.

By 2050, NSW is likely to experience an increase in mean maximum and minimum temperatures of $1-3^{\circ} \mathrm{C}$ across the state with most of the change occurring in autumn, winter and spring. NSW will generally be wetter in the warmer months but drier in winter, particularly in the south-west, where a reduction in winter rain of between $20 \%$ and $50 \%$ has been projected. ${ }^{1}$

Environmental changes of this proportion will have both acute and insidious health impacts. For example, more frequent heat waves will result in increased hospital admission for heat-related illness. Changes to the social, economic and cultural fabric of communities, particularly in rural areas, as a result of more frequent and longer lasting droughts will also affect the mental health burden in those communities. ${ }^{2}$ The flow-on impacts on infrastructure management and health service provision are yet to be accurately quantified; nevertheless, it does suggest that significant planning and adaptation will be required.

In NSW, the Department of Environment and Climate Change (DECC) is the lead agency for responding to climate change. NSW Health has been working with DECC through the Greenhouse Innovation Fund to develop a range of adaptation initiatives.

These include:

- The development and testing of a public health heat response plan by Northern Sydney Central Coast Area Health Service in 2007.

- The development, implementation and evaluation of a range of targeted heat health messages by Greater Southern Area Health Service.

- North Coast Area Health Service is harnessing the opportunities offered by climate change mitigation and adaptation to promote healthy lifestyle behaviours - increased physical activity, healthy diets and social connectedness.

The focus of NSW Health's climate change adaptation activity in 2009 will be heat-related illness adaptation, regional health vulnerability assessment and regional adaptation planning.

\section{References}

1. New South Wales Government Department of Environment and Climate Change. Regional Climate Change Impacts. Available from: http://www.environment.nsw.gov.au/climateChange/regionsummary.htm [Updated 20 November 2008; Cited 12 December 2008]

2. Sartore GM, Kelly B, Stain HJ. Drought and its effect on mental health: how GPs can help. Aust Fam Physician 2007; 36: 990-3. 


\title{
Box 2. National Climate Change Adaptation Research Network - human health
}

This network was recently established to improve Australian knowledge about climate change adaptation and human health to enable decision-making by government, industry and communities. The objectives of the network are to:

- foster interdisciplinary research and emerging research methods (time-series methods, spatial analysis, systems-based modelling of complex ecological relationships and processes and scenario-based modelling of future health risks);

- build research and decision-making capacity by mentoring and support for early and mid-career researchers and policymakers;

- facilitate collaboration between researchers, policymakers and practitioners, including involvement across the research cycle (scoping, planning, analysis, reporting); and

- communicate research findings in ways relevant to different sectors and varying regional conditions to strengthen Australia's capacity to anticipate, adapt to and mitigate the human health consequences of climate change.

The Australian National University is the Network host. Further information is available from:

http://www.nccarf. edu.au/?q=node/24

\section{Box 3. Glossary*}

\begin{abstract}
Adaptation
Initiatives and measures to reduce the vulnerability of natural and human systems against actual or expected climate change effects. Various types of adaptation exist, for example, anticipatory and reactive, private and public and autonomous and planned. Examples include heat wave early warning systems and growing more vegetation in cities to reduce the urban heat island.

\section{Adaptive capacity}

The capabilities, resources and institutions of a country, region or individual to implement effective adaptation measures.

\section{Co-benefits}

The benefits of policies implemented for various reasons at the same time, acknowledging that most policies designed to address greenhouse gas mitigation have other, often at least equally important, rationales (e.g. related to objectives of development, sustainability, equity and health).
\end{abstract}

\section{Extreme weather event}

A weather event that is rare at a particular place and time of year. Definitions of rare vary, but an extreme weather event would normally be as rare as or rarer than the 10th or 90th percentile of the observed probability density function. By definition, the characteristics of what is called extreme weather may vary from place to place in an absolute sense. Single extreme events cannot be simply and directly attributed to anthropogenic climate change, as there is always a finite chance the event in question might have occurred naturally.

\section{Greenhouse gas (GHG)}

Greenhouse gases are those gaseous constituents of the atmosphere, both natural and anthropogenic, that absorb and emit radiation at specific wavelengths within the spectrum of thermal infrared radiation emitted by the Earth's surface, the atmosphere itself, and by clouds. This property causes the greenhouse effect. Water vapour $\left(\mathrm{H}_{2} \mathrm{O}\right)$, carbon dioxide $\left(\mathrm{CO}_{2}\right)$, nitrous oxide $\left(\mathrm{N}_{2} \mathrm{O}\right)$, methane $\left(\mathrm{CH}_{4}\right)$ and ozone $\left(\mathrm{O}_{3}\right)$ are the primary greenhouse gases in the Earth's atmosphere.

\section{Mitigation}

Technological change and substitution that reduce resource inputs and emissions per unit of output. Although several social, economic and technological policies would produce an emission reduction, with respect to climate change, mitigation means implementing policies to reduce greenhouse gas emissions and enhance sinks.

\section{Resilience}

The ability of a social or ecological system to absorb disturbances while retaining the same basic structure and ways of functioning, the capacity for self-organisation, and the capacity to adapt to stress and change.

\section{Vulnerability}

The degree to which a system is susceptible to, and unable to cope with, adverse effects of climate change, including climate variability and extremes. Vulnerability is a function of the character, magnitude and rate of climate change and variation to which a system or individual is exposed as well as its sensitivity and its adaptive capacity.

*Source: Climate Change 2007: Synthesis Report. Contribution of Working Groups I, II and III to the Fourth Assessment Report of the Intergovernmental Panel on Climate Change [Core Writing Team, Pachauri, R.K. and Reisinger, A. (eds.)]. Geneva: IPCC; 2007.

co-benefits in the food system, examining the link between industrial food production and food problems such as diets poor in nutrients and loss of control over food choices. Climate change threatens further food shortages. The authors explain why promoting urban agriculture is sustainable and brings multiple health and environmental benefits.

Prolonged droughts over recent years in Australia have exacerbated bushfires and in 2003 NSW and Victoria 
experienced major bushfires and widespread smoke pollution. Kolbe and Gilchrist evaluate the effectiveness of public health advisories about bushfire smoke pollution provided to Albury residents in the summer of 2003.

In the concluding paper, Capon and colleagues argue for systems approaches in governance to address climate change. They argue for a focus on the underlying causes of problems such as climate change and the obesity epidemic. Effective governance will necessitate moving beyond 'silo' approaches to integrative policy and planning.

Climate change, an environmental health issue of unprecedented scale and complexity, necessitates new ways of thinking, communicating and acting for public health. ${ }^{4} \mathrm{We}$ hope this special issue of the Bulletin will encourage public health workers to take on these challenges.

Box 3 contains a glossary of terms used in this issue that may be unfamiliar to Bulletin readers.

\section{References}

1. World Health Organization. Protecting health from climate change - World Health Day 2008. Geneva: WHO, 2008.

2. McMichael AJ, Woodruff RE, Hales S. Climate change and human health: Present and future risks. Lancet 2006; 367 : 859-69. doi:10.1016/S0140-6736(06)68079-3

3. St. Louis ME, Hess JJ. Climate change: impacts on and implications for global health. Am J Prev Med 2008; 35: 527-38. doi:10.1016/j.amepre.2008.08.023

4. Frumkin H, McMichael AJ. Climate change and public health: Thinking, communicating, acting. Am J Prev Med 2008; 35: 403-10. doi:10.1016/j.amepre.2008.08.019

5. National Climate Change Adaptation Research Facility. Human health and climate change: National adaptation research plan. Available from: http://www.nccarf.edu.au/?q=node/42 (Cited 12 December 2008) 